\title{
Locomotor disability in very elderly people: value of a programme for screening and provision of aids for daily living
}

\author{
Deborah Hart, Ann Bowling, Margaret Ellis, Alan Silman
}

\begin{abstract}
Objective-To assess the prevalence of potentially reversible locomotor disabilities in elderly subjects and the cost effectiveness of providing aids for daily living.

Design-Population based randomised controlled trial of subjects aged $\geqslant 85$ living independently in an inner London borough.

Setting-21 Electoral wards of the London Borough of Hackney.

Subjects -1255 Subjects aged $\geqslant 85$ living in their own home whose names were obtained from general practitioner lists and cross checked against the electoral register, 511 of whom were subsequently found to be ineligible. Of the 744 remaining, those with disability on screening were randomised and allocated to an intervention group (36) or a control group (43), in which intervention was postponed until four weeks, after the follow up assessment. Subjects with aids supplied previously were excluded from the intervention phase.
\end{abstract}

Interventions - Provision of raised toilet seat, teapot tipper, tap turner, shoe horn and elastic laces, and double handled saucepan.

Main outcome measures-Degree of difficulty (grades 1-4) with specific tasks (getting on and off a toilet, pouring from a teapot into a cup, turning taps on and off, carrying a saucepan of standard weight, and putting on shoes) and time taken to perform them.

Results $-545(73 \%)$ Of the 744 eligible subjects assessed; 428 had no disability and 118 had difficulty with at least one task. Some had had their disability recognised before the study and already had aids, representing half of those with difficulty getting on and off the toilet but $24 \%$ for putting on shoes and $13 \%$ for pouring from a teapot and turning on a tap. The mean number of difficulties was similar between the groups (intervention group 1.7 , control group 1.6). Time taken to complete the tasks corresponded with the observed grade of difficulty. All aids were associated with reduced difficulty according to observer assessment (\% improvement intervention group $v$ control group: raised toilet seat, $71 v 13$; teapot tipper $100 v 33$; tap turner $100 v 0$; saucepan $88 v 0$; shoe horn $50 v 13$ ) and time taken to complete the tasks. A cost benefit analysis of this screeningintervention programme suggested a total cost of $£ 32$ per individual benefit.

Conclusions-Appreciable degrees of unrecognised locomotor disability are detected on screening of very elderly people living independently. Providing aids offers a feasible and cost effective means of improving function in such people.

\section{Introduction}

As the numbers of very elderly people (age $\geqslant 85$ ) in the population increases so does the responsibility of health and social services to deal with the increasing amounts of disability resulting from the increased prevalence of chronic disease in this age group. The ideal goal of maintaining elderly people within the community highlights the need for an efficient service to identify disability and to offer successful intervention.

In a recently published OPCS survey on all forms of disability it was estimated that, of six million adults in Great Britain who had at least one disability, nearly half were aged 70 and over. ${ }^{\prime}$ A similar survey confined to an inner London borough, in which greater numbers of elderly people live alone, often in more deprived areas, estimated that $43 \%$ of men and $61 \%$ of women aged over 75 living at home were disabled. Task specific studies have examined degrees of disability in individual activities of daily living. In a survey sponsored by the Department of Health and Social Security, Hunt found that decreasing abilities to carry out domestic activities rose steeply with increasing age $\mathrm{a}^{3}$; between $13 \%$ and $25 \%$ of people aged over 85 were unable to open jars, carry a saucepan, or even make a cup of tea. A more recent study of very elderly people showed that only $43 \%$ were able to get on and off the toilet without disability. ${ }^{4}$ Many conditions, such as sensory, neurological, and musculoskeletal disorders, may contribute to locomotor disability; osteoarthritis and rheumatoid arthritis are perhaps the most common. ${ }^{5}$ The main effect of these disorders is to limit mobility and use of arms and legs in carrying out everyday tasks.

An additional goal of screening for disability is to elucidate whether existing services are effective in reducing or resolving the problems. ${ }^{5}$ This requires a population based survey to identify those who might benefit from a service but who are not already receiving it. Before this type of screening may be adopted as a practical policy, however, the effectiveness of available interventions, such as the provision of suitable aids and appliances, requires evaluation. Surprisingly little research has been carried out on this topic, and few randomised controlled trials have been conducted. There is perhaps a widespread assumption that with accurate diagnostic assessment providing an appropriate aid will be of benefit. The Department of Health and Social Security commissioned a series of studies comparing the use of different aids for the same activity, ${ }^{6}$ but the question of whether providing equipment after population screening is cost effective is unanswered.

This study aimed therefore at carrying out a population based survey to determine the prevalence of disability in locomotor function of the very elderly population living independently in an inner London borough and was restricted to considering five types of disability whose associated handicap was thought to be reversible by providing simple equipment. This assumption was tested in a randomised controlled trial of the efficacy of five simple aids - a raised toilet seat, 
teapot tipper, lightweight double handled saucepan, tap turner, and long handled shoe horn - in reducing disabilities in subjects found on assessment to have difficulties in one or more of these activities of daily living. In addition, the benefits of the intervention were considered relative to the costs of both the screening assessment and providing the suitable equipment.

\section{Subjects and methods SUBJECTS}

The study population consisted of all persons aged $\geqslant 85$ living in their own home in the London Borough of Hackney and was originally identified from the general practitioner lists from the local family practitioner committee, which had information available on age. The list was subsequently checked against the current electoral register, and the 1255 subjects common to both lists were apparently eligible for the study. Subsequent attempts to contact them, however, showed that 511 were ineligible: 122 had died, 256 had moved either from the borough or to an unknown address, 81 were in residential care, and a further 52 subjects were excluded, including 49 who were bedridden or dependent on a carer and three who did not speak English; this left 744 available for study.?

\section{ASSESSMENT}

All subjects were offered a visit in their own home to assess their level of ability in daily activities. The assessments were conducted by a trained occupational therapist (DH). Five activities of daily living were assessed: getting on and off a toilet, pouring from a teapot into a cup, turning taps on and off to fill a one pint jug, carrying a saucepan containing a standard weight, and putting on shoes. These tasks were chosen for two reasons. Firstly, their use showed involvement of a wide range of joints and muscle groups: hip, knee, shoulder, elbow, wrist, and small joints of the hands, and, secondly, the study aimed at detecting disabilities for which simple equipment was available that might reduce the level of handicap.

A functional assessment of the five tasks was devised with a four point graded scale (1-4) to rate the degree of difficulty perceived by the observer (appendix). A score of $\geqslant 2$ indicated clinically important difficulty, and a score of 4 was given when the subject was unable to complete the task after two minutes (or three minutes for putting on shoes). The assessment procedures were tested for interobserver variation in a pilot study comparing the results obtained by the study observer and three independent occupational therapists who were familiar with functional indices. The instructions for completing the task and the criteria used for grading the ability were made more stringent during the piloting. The final standardised procedure for the assessment of each task (appendix) was adopted when in at least $90 \%$ of the assessments the observers agreed on grade of ability, and, when there was disagreement, there was a difference of no more than one grade. As an external check on the grading scale used the time taken to complete each task was recorded inconspicuously with a stopwatch. Start and stop procedures for each task were standardised to ensure comparability in timing.

\section{INTERVENTION AND FOLLOW UP}

The screening survey was designed such that subjects with identified difficulties in any of the five tasks were automatically recruited into a randomised controlled trial of the benefits of providing suitable aids. Screen positive subjects in 14 of the 21 electoral wards surveyed were allocated to receive equipment either immediately (intervention group) or after the trial (control group). Those in the remaining seven wards were subject to a separate intervention study. The subjects living in the 14 wards before screening were randomised by their electoral ward of residence stratified by size and broad social constitution of the wards with tables of random numbers. This method of allocating subjects was chosen to reduce the chance of "contamination" due, for example, to subjects in the same block of flats being separately allocated to immediate or postponed intervention.

The aids issued were a four inch raised toilet seat ("Kirby" or "Derby"), a teapot tipper/pourer, a tap turner "'Tapturn," or "Crystal" for modern style taps), a 25 inch metal shoe horn with a hooked polyvinylchloride handle coupled with elastic laces ("Soesi") (all from Homecraft, Kirby in Ashfield), and a six inch double handled lightweight casserole type saucepan (Salt and Dukes, Birmingham). They were issued at the time of assessment to subjects randomised to the intervention group, and subjects in both groups were reassessed after four weeks. Those initially randomised to the control group who still had disability on reassessment were then either issued with the trial aids or referred to the local authority's occupational therapy service, which provides all these aids. This four week delay in supplying the control group was considered to be ethically acceptable and compared favourably with that associated with the routine services available for such provision. The study had ethical approval from the local district health authority.

\section{METHODS OF REASSESSMENT}

All subjects were reassessed at four weeks after screening for degree of difficulty and time taken to complete the tasks. The same observer carried out the initial and follow up assessments to maintain rapport and encourage compliance, and thus the trial was not observer blinded. This would have been impossible in any case as the reassessments in the intervention group required the use of the aids provided. A crude check of observer bias was attempted with an independently trained observer who jointly made 16 reassessments with the main observer; in only one instance did the grade of difficulty recorded differ.

The change in the degree of difficulty between assessments was scored as: improved $(+)$, no change $(0)$, and deteriorated (-). As the numbers in some cells were small the categories of no change and deteriorated were combined for analysis, and the resulting $2 \times 2$ contingency tables were analysed by Fisher's exact test. The standard error of the differences between the percentage improvement rates and in the change in time taken to perform the tasks between the two study groups were calculated and the results expressed with $95 \%$ confidence intervals.

\section{Results}

\section{SCREENING}

In all, $545(73 \%)$ of the 744 eligible subjects were assessed; 100 refused to be seen, either by sending back the original invitation or when visited at home, and 99 were neither at home when visited nor was there a response from near neighbours about them.

Some of the 545 subjects were not assessed for all five tasks. An assessment was not done if before the study they had been identified as having specific disability and had a suitable aid. Further, if the subject relied on another person to do a task (for example, some elderly people did not cook their own food and thus never carried a saucepan) they were excluded from assessment for that task. Two degrees of perceived difficulty were used in the analysis, "any difficulty," representing grade 2 or worse, and "major difficulty," 
representing grades 3 and 4 combined, there being only very few subjects in the grade 4 category.

Table I shows the proportions of people with difficulties for each of the five tasks. These ranged from $5 \%$ for those with difficulty pouring from the teapot, to $13 \%$ for those with difficulties getting on and off the toilet. The proportion with major difficulties was much lower. Some subjects had difficulties with more than one of the tasks; $428(78 \%)$ people had no difficulty and $118(22 \%)$ had difficulty in at least one task, 49 $(9 \%)$ had difficulties in at least two tasks or more and 22 (4\%) with three tasks or more. Some subjects had had their disability recognised before the study and had been issued with appropriate aids (table I). Their frequency in the population was further expressed as a proportion of the total screened population with that disability. For getting on and off the toilet the number already having a raised toilet seat represented only half of those who had a need. The proportions of those with a disability in the other groups who already had aids were much lower.

As a check on the grading system used the time taken to complete each of the tasks was measured. The increase in time corresponded well with the observed grade of difficulty (table II).

\section{INTERVENTION}

Subjects were excluded from the intervention phase if they had had aids supplied previously. All eligible

TABLE I-Proportion of subjects with and without difficulty in performing tasks and proportion with identified disability and aid previously

\begin{tabular}{|c|c|c|c|c|c|c|c|}
\hline \multirow[b]{2}{*}{ Task } & \multirow[b]{2}{*}{ No } & \multicolumn{3}{|c|}{ No (\%) with: } & \multirow{2}{*}{$\begin{array}{l}\text { No }(\%)^{\star} \\
\text { with aid } \\
\text { previously } \\
\text { (b) }\end{array}$} & \multirow{2}{*}{$\begin{array}{l}\text { Total No } \\
\text { with } \\
\text { disability } \\
(\mathbf{a}+\mathbf{b})\end{array}$} & \multirow{2}{*}{$\begin{array}{c}\text { \% With aid } \\
\text { previously } \\
(\mathrm{b} / \mathrm{a}+\mathbf{b})\end{array}$} \\
\hline & & $\begin{array}{c}\text { No } \\
\text { difficulty }\end{array}$ & $\begin{array}{c}\text { Any } \\
\text { difficulty (a) }\end{array}$ & $\begin{array}{c}\text { Major } \\
\text { difficulty }\end{array}$ & & & \\
\hline Getting on and off toilet & 486 & $425(87 \cdot 4)$ & $61(12 \cdot 6)$ & $14(2.9)$ & $60(11 \cdot 0)$ & 121 & $49 \cdot 6$ \\
\hline Pouring from teapot & 502 & $475(94 \cdot 6)$ & $27(5.4)$ & $6(1 \cdot 2)$ & $4(0 \cdot 7)$ & 31 & $12 \cdot 9$ \\
\hline Turning on tap & 505 & $477(94.5)$ & $28(5 \cdot 5)$ & $4(0.8)$ & $4(0.7)$ & 32 & $12 \cdot 5$ \\
\hline Carrying saucepan & 488 & $459(94 \cdot 1)$ & $29(5.9)$ & $4(0.8)$ & $1(0 \cdot 2)$ & 30 & $3 \cdot 3$ \\
\hline Putting on shoes & 526 & $482(91.6)$ & $44(8.4)$ & $8(1.5)$ & $14(2 \cdot 6)$ & 58 & $24 \cdot 1$ \\
\hline
\end{tabular}

ॠAs percentage of total study population $(n=545)$.

TABLE II-Relation between time spent on each task and difficulty experienced ${ }^{\star}$

\begin{tabular}{lrrr}
\hline & \multicolumn{3}{c}{ Mean (SD) time (s) } \\
\cline { 2 - 4 } Task & Grade 1 & Grade 2 & \multicolumn{1}{c}{ Grade 3 } \\
\hline Getting on and off toilet & $3 \cdot 4(1 \cdot 3)$ & $7 \cdot 2(3 \cdot 0)$ & $10 \cdot 8(4 \cdot 2)$ \\
Pouring from teapot & $4 \cdot 7(1 \cdot 5)$ & $6 \cdot 2(2 \cdot 8)$ & $12 \cdot 3(4 \cdot 4)$ \\
Turning on taps & $4 \cdot 9(1 \cdot 3)$ & $7 \cdot 2(3 \cdot 1)$ & $7 \cdot 9(1.9)$ \\
Carrying saucepan & $4 \cdot 2(1 \cdot 3)$ & $7 \cdot 6(2 \cdot 9)$ & $10 \cdot 8(3 \cdot 9)$ \\
Putting on shoes & $12 \cdot 3(3 \cdot 9)$ & $19 \cdot 9(6 \cdot 7)$ & $27 \cdot 9(8 \cdot 4)$ \\
\hline
\end{tabular}

^Excluding subjects with grade 4 difficulty (as task was not completed).

TABLE III - No of subjects allocated to each intervention group

\begin{tabular}{lcc}
\hline Task causing difficulty & $\begin{array}{c}\text { Immediate } \\
\text { intervention }\end{array}$ & $\begin{array}{c}\text { Postponed } \\
\text { intervention }\end{array}$ \\
\hline Getting on and off toilet & 19 & 23 \\
Pouring from teapot & 11 & 9 \\
Turning on tap & 10 & 9 \\
Carrying saucepan & 9 & 12 \\
Putting on shoes & 12 & 16 \\
\hline
\end{tabular}

subjects in the first 14 of the 21 total electoral wards in Hackney surveyed were studied, and 36 with at least one disability were allocated to immediate intervention and 43 to postponed intervention. Only one subject after allocation had a grade 4 difficulty at the first screening; she had been unable to carry a saucepan and had been allocated to the postponed intervention group. Some subjects had difficulty with more than one task; table III shows the numbers of these subjects allocated to each group. The mean number of difficulties was similar in both groups $(1.7$ for intervention, 1.6 for control) with no difference in the number of subjects with three or more difficulties. The study was population based and the numbers eligible for intervention were determined by the results of the screening survey in the 14 wards studied. The numbers of subjects entered into the trial were small but it was decided that to be cost effective the interventions should be of potential major benefit. On the assumption that without intervention about a 10th of subjects would improve on reassessment whereas intervention might improve disability in at least $70 \%$, the number of subjects recruited were sufficient to have an $80 \%$ power to detect a significant difference $(\alpha=0.05)$ for all interventions except difficulty with putting on shoes.

One person in the intervention group refused to use the aids and one in each group refused to be reassessed. Another subject who had been given three aids was in hospital at the time of reassessment. The subjects in both groups were well matched for age and sex with a five:one female excess in both groups. There was a convincing improvement in ability with all the interventions tested (table IV). Only in the case of the footwear aids were the results not overwhelmingly in favour of the intervention.

The change in time taken to perform each task, as a more objective and mathematically continuous scale measure, was also recorded (table V). There was a mean reduction in time taken with all five interventions compared with virtually no change when providing aids was postponed. The variances, however, were high, and the upper $95 \%$ confidence limits for the difference in reduction in time between the groups showed that these reductions were significant for only the toilet seat aid and double handled saucepan.

\section{COST BENEFIT}

The net percentage benefit (the percentage improving in the intervention group minus the percentage improved in the control group) may be calculated from the results (table IV) and combined with the percentage yield from screening (table I) to calculate the percentage benefit per 100 screened persons. The costs of providing equipment for all those detected on screening was calculated as the product of the cost of the individual item and the percentage positive rate at screening for that disability. Table VI shows these percentage benefits and equipment costs for a notional population of 100 .

In this inner city area the mean cost of employing an occupational therapist, allowing for travelling time, was $£ 4.38$ per visit and $50 \mathrm{p}$ travel costs to do all

TABLE IV - Change in perceived degree of difficulty in reassessment. Unless otherwise stated, figures are numbers of subjects

\begin{tabular}{|c|c|c|c|c|c|c|c|c|c|c|c|c|}
\hline \multirow[b]{2}{*}{ Aid } & \multirow[b]{2}{*}{$\begin{array}{c}\text { No of } \\
\text { subjects }\end{array}$} & \multicolumn{4}{|c|}{ Intervention group } & \multirow[b]{2}{*}{$\begin{array}{c}\text { No of } \\
\text { subjects† }\end{array}$} & \multicolumn{4}{|c|}{ Control group } & \multirow{2}{*}{\multicolumn{2}{|c|}{$\begin{array}{c}95 \% \text { Confidence } \\
\text { interval for \% } \\
\text { difference } \\
\text { improvement } \\
\text { p Value } \\
\text { between groups }\end{array}$}} \\
\hline & & + & 0 & - & $\begin{array}{c}(\% \\
\text { Improved })\end{array}$ & & + & 0 & - & $\begin{array}{c}(\% \\
\text { Improved })\end{array}$ & & \\
\hline Raised toilet seat & 7 & 12 & 5 & 0 & (71) & 23 & 3 & 17 & 3 & (13) & 0.0003 & $27 \cdot 2$ to $87 \cdot 9$ \\
\hline Teapot tipper & 8 & 8 & 0 & 0 & (100) & 9 & 3 & 5 & 1 & (33) & 0.0068 & $21 \cdot 2$ to 100 \\
\hline Tap turner & 8 & 8 & 0 & 0 & (100) & 9 & 0 & 7 & 2 & & $0 \cdot 0000$ & $52 \cdot 5$ to 100 \\
\hline Double handled saucepan & 8 & 7 & 1 & 0 & (88) & 12 & 0 & 9 & 3 & & $0 \cdot 0000$ & $43 \cdot 6$ to 100 \\
\hline Shoe horn & 10 & 5 & 5 & 0 & $(50)$ & 15 & 2 & 10 & 3 & (13) & $0 \cdot 04$ & $0 \cdot 8$ to $72 \cdot 6$ \\
\hline
\end{tabular}

^Fisher's exact test for improvement $v$ remainder.

tThree subjects in intervention group and one in the control group were not reassessed for all aids (see text). 
TABLE $\mathrm{v}-$ Mean change in time taken to complete task

\begin{tabular}{|c|c|c|c|c|c|c|}
\hline \multirow[b]{2}{*}{ Task } & \multicolumn{2}{|c|}{ Intervention group } & \multicolumn{2}{|c|}{ Control group } & \multirow[b]{2}{*}{ Difference } & \multirow[b]{2}{*}{$\begin{array}{l}95 \% \text { Confidence } \\
\text { interval }\end{array}$} \\
\hline & $\begin{array}{c}\text { No of } \\
\text { subjects }\end{array}$ & $\begin{array}{c}\text { Mean } \\
\text { change }\end{array}$ & $\begin{array}{c}\begin{array}{c}\text { No of } \\
\text { subjects }\end{array} \\
\end{array}$ & $\begin{array}{c}\text { Mean } \\
\text { change }\end{array}$ & & \\
\hline Getting on and off toilet & 17 & $-2 \cdot 1$ & 23 & +0.6 & $-2 \cdot 7$ & $(-4.8$ to -0.6$)$ \\
\hline Pouring from teapot & 8 & $-4 \cdot 1$ & 9 & $-0 \cdot 6$ & $-3 \cdot 5$ & $(-7 \cdot 2$ to $+0 \cdot 3)$ \\
\hline Turning on tap & 8 & $-1 \cdot 3$ & 9 & 1.5 & $-2 \cdot 8$ & $(-6 \cdot 7$ to $+1 \cdot 1)$ \\
\hline Carrying saucepan & 8 & $-4 \cdot 0$ & $11^{\star}$ & $0 \cdot 8$ & $-4 \cdot 8$ & $(-8 \cdot 3$ to $-1 \cdot 3)$ \\
\hline Putting on shoes & 10 & $-2 \cdot 0$ & 15 & $0 \cdot 4$ & $-2 \cdot 4$ & $(-8 \cdot 9$ to $+4 \cdot 1)$ \\
\hline
\end{tabular}

*One subject in the control group who had grade 4 difficulty on initial assessment was excluded.

TABLE VI-Percentage benefits and equipment costs of screening a population of 100 people

\begin{tabular}{|c|c|c|c|c|c|}
\hline \multirow[b]{2}{*}{ Task } & \multirow[b]{2}{*}{$\begin{array}{l}\text { Positive } \\
\text { (a) }\end{array}$} & \multirow[b]{2}{*}{$\begin{array}{c}\% \text { Benefiting } \\
\text { from equipment } \\
\text { (b) }\end{array}$} & \multirow[b]{2}{*}{$\begin{array}{c}\text { No benefiting } \\
\text { (a.b) }\end{array}$} & \multicolumn{2}{|c|}{ Cost of equipment $(\mathfrak{£})$} \\
\hline & & & & $\begin{array}{l}\text { Per item } \\
\text { (c) }\end{array}$ & $\begin{array}{l}\text { Per } 100 \\
\text { screened } \\
\text { (a.c) }\end{array}$ \\
\hline Getting on and off toilet & $12 \cdot 5$ & 57 & $7 \cdot 2$ & 22.40 & 280.00 \\
\hline Pouring from teapot & $5 \cdot 4$ & 67 & $3 \cdot 6$ & 5.95 & 32.13 \\
\hline Turning on tap & $5 \cdot 5$ & 100 & $5 \cdot 5$ & 2.50 & 13.75 \\
\hline Carrying saucepan & $6 \cdot 1$ & 88 & $5 \cdot 3$ & 4.60 & 28.06 \\
\hline Putting on shoes & $8 \cdot 3$ & 37 & $3 \cdot 0$ & 1.85 & 15.36 \\
\hline Total & & & $26 \cdot 6^{\star}$ & & 369.30 \\
\hline
\end{tabular}

«Total of individual item benefits.

five assessments on a single person. Thus 100 visits generated employee costs of $£ 488$ and equipment costs of $£ 369$, a total cost of $£ 857$ or $£ 8.57$ per person screened (table IV). Screening and intervention of 100 people would yield 27 individual item benefits at a cost per benefit achieved of $£ 31.70$. If the screening had been limited to only one of the five areas and assuming that this reduced the initial overall assessment time by half (travel time would remain the same) the cost benefit for each of the individual disabilities screened would be: toilet seat, $£ 73.60$; teapot, $£ 78.30$; tap turner, £47.80; saucepan, £52.50; shoe horn, £88.00. The cost benefit for each item is a product of the prevalence of the disability, the percentage benefit, and the cost of the equipment. Screening for all five abilities concurrently is more cost effective.

\section{Discussion}

In this study we attempted to identify and assess every person aged 85 and over living at home in the London Borough of Hackney; the final proportion of all available people assessed was $73 \%$. If the refusers and those not at home were, for example, more able than those we saw our figures might overestimate the prevalence of disability. This is difficult to test, but an estimate of this bias may be derived from comparing the results of the subjects who responded initially and those who refused first time and agreed to be seen on a subsequent request. Thus $8 / 43(19 \%)$ of initial non-responders were assessed as having one difficulty or more compared with $118 / 502(24 \%)$ of the initial responders. This difference was not significant, although it was in the direction of the initial nonresponders being more able.

Our data are not total population estimates of disability in very elderly subjects but reflect the situation only in those living at home with some degree of independence. The true estimates in the total population are probably higher as people who were totally dependent on a carer and those living in residential care within the borough were excluded from the study. By contrast, it should be emphasised that in the population studied 415 subjects had no disability in the tasks studied.

Although the assessment methods used had been standardised to reduce interobserver variation, all the assessments were carried out by a single trained observer. To ensure that the interobserver variation had not changed a second observer was used at intervals during the study to monitor the standardisa- tion and to assess each subject independently. Analysis of these joint assessments showed concordance of $88 \%$, with a difference of only one grade in those instances of disagreement.

This study showed that the, detection of specific and previously undetected handicaps in the very elderly population, coupled with appropriate intervention, can produce a worthwhile improvement in functioning of an average one task benefit for every four persons screened. The effectiveness of occupational therapy aids in accurately assessed disabilities is commonly taken as being self evident, although patient reluctance, ${ }^{8}$ inaccurate diagnosis, and poorly designed equipment can limit the effectiveness of aids provided. This study reports the relative improvement in handicap that may be expected in "real life," although careful clinical appraisal might suggest other strategies for reducing handicap. The response to an intervention may in part depend on disability elsewhere. The numbers of subjects with multiple disabilities were similar in both groups and thus the results of the intervention study were unlikely to be biased in this respect. The observer was not blind to the intervention provided, and those receiving the intervention likewise were manifestly aware of the aid provided to complete a task. It is difficult therefore to separate out the relative contributions of encouragement by the therapist, placebo response by the individual, and value of the equipment in reducing handicap. The delayed intervention group served solely to show that in the absence of such intervention the handicaps remained, with little evidence of improvement on reassessment. Four subjects were not followed up, of whom three were from the intervention group. Their inclusion, even if they had reported no benefit, is highly unlikely to have altered the major conclusions from the findings presented in table IV. Only a single follow up assessment was undertaken and it would obviously be of interest to attempt further follow up to determine whether the improvements were maintained. There are other important areas of disability - in bathing, dressing, etc-that are potentially reversible by aids ${ }^{8}$ but were not assessed in this study, which it would be important to consider in future work.

The cost effectiveness of this type of screening and intervention was also assessed. At a total cost of about $£ 8$ per person or $£ 32$ per improvement in function, the financial implications to health and local authorities seem to be modest when set against the potential improvement in function. Pre-emptive screening and intervention in elderly people, although inappropriate in many areas of health, might be a valuable approach in improving the aspects of locomotor function considered in the study.

In conclusion, it seems that there were important degrees of unrecognised disability in this age group in that at least $22 \%$ had sufficient difficulty to justify simple interventions available from community services. Further, most of those experiencing difficulties in these activities of daily living did not already have aids that could improve their function, although in the case of a simple aid such as a shoe horn many disabled people might be expected to equip themselves. ${ }^{9}$ Therefore, this study suggests that this level of one off screening of very elderly people living at home is justified. Most of the conditions for which such screening is appropriate are stable in subjects by the age of 85 , and screening would only be required once, perhaps when that age was reached. An average health district or general practice would have relatively few people to be screened each year, and screening could be combined with other aspects of pre-emptive care and health education. In this study the assessments were undertaken by a trained occupational therapist, but 
other professionals more usually found in the primary health care team could be trained for this task.

We thank North East Thames Regional Health Authority for providing financial assistance through the LORS grant scheme, the Tower Hamlets District Occupational Therapy Service for assistance with evaluating the assessments, and staff of the department of community medicine, St Leonard's Hospital, who helped to produce the register of subjects.

1 Martin J, Meltzer H, Elliot D. The prevalence of disability in adults. OPCS surveys of disability in Great Britain. Report 1 . London: HMSO, 1988.

2 Patrick DL, Darby SC, Green S, Horton G, Locker D, Wiggins RD. Screening for disability in the inner city. $\mathcal{F}$ Epidemiol Community Health 1981;35:65-70. 3 Hunt A. The elderly at home. Survey for DHSS. London: HMSO, 1978.

4 Clarke M, Clarke S, Odell A, Jagger C. The elderly at home: health and socia status. Health Trends 1984;16:3-7.

5 Warren $M$. The prevalence of disability: measuring and estimating the needs of disabled people in the community. Public Health 1987;101:333-41.

6 Department of Health and Social Security. Disability equipment assessment programme reports. 1980-1988. London: DHSS, 1980-8.

7 Hart D, Bowling A, Silman AJ. Accuracy of electoral registers and family practitioner committee lists for population studies of the very elderly. I Epidemiol Community Health 1989:43:391-4.

8 Mulley G, ed. Everyday aids and appliances. London: British Medical Journal, 1989.

9 White EG, Mulley GP. Footwear worn by the over 80 s: a community survey. Clinical Rehabilitation 1989;3:23-5.

(Accepted 18 May 1990)

\section{Appendix}

\section{FUNCTIONAL GRADES FOR ACTIVITIES OF DAILY LIVING}

Grade 1-Easily completes task as expected of an elderly person with no disability - that is, he or she may take longer than a younger adult.

Grade 2-Completes task, but with a little difficulty. The movement is continuous, but may show one or more of the elements listed below.

Grade 3-Completes task, but with much difficulty. The movement is not continuous and may show one or more of the elements listed below.

Grade 4-Unable to complete task.

SPECIFIC TASKS

Getting on and off toilet

Grade 2:

Reaches for support.

Comments on difficulty.

Unsteady but remedies this while sitting or standing.

Grade 3:

Continually reaches for any support.

Comments more than once on difficulty.

Unbalanced, unsteady, unsafe, raises self, and attempts process several times.

Flops down and unable to control movement, becomes anxious.

\section{Pouring tea}

Grade 2:

May be unsteady while lifting pot but can control movement.

May spill tea once but remedies position.

Is aware of safety and when cup is full.

Grade 3:

Unsteady and cannot control movement.

Is anxious about inability.

Spills tea more than once and cannot remedy position.

Is unaware of safety and cannot anticipate actions for when cup is full.

\section{Turning taps on and off}

Grade 2:

Has initial difficulty in turning on tap due to stiffness of tap.

Turns on and off by sustaining a continuous turn.

Anticipates action to turn off when jug is full, a little overflows.

Grade 3:

Has initial problem in reaching and grasping tap.

Makes more than one attempt, takes hand away more than once.

Unable to anticipate action when jug is full, a lot overflows.

\section{Carrying saucepan}

Grade 2:

Lifts pan, but needs to check direction of hob once.

May need to rest pan once but can control movement.

May slosh water in pan but is aware of safety.

May need more than one attempt to settle pan on hob, not more than two.

Grade 3:

Makes more than one attempt to lift.

Unaware of direction before starting.

Needs to rest pan and shows weakness.

Has difficulty in controlling pan.

Spills water, cannot keep pan level.

Unaware of safety.

Needs several attempts to settle pan on hob.

Putting on shoes

Grade 2:

Makes more than two attempts to put on each shoe.

Reaches down, and lifts leg no more than twice.

Needs to pause once before finally adjusting shoe.

May be unsteady but is able to control balance.

Grade 3:

Makes more than two attempts to put on each shoe.

Reaches down, and lifts leg more than twice.

Unsteady and loses balance, needing to raise and pause before carrying on.

Leaves shoe half on and pauses before finishing.

\section{THE MEMOIR CLUB}

Like the inheritance of stature, intelligence, and hypertension, criticism of modern medicine is multifactorial. Some, like Ivan Illich, deny any virtue, regarding medicine as a conspiracy against the public, and even looking on the relief of pain as a hindrance to human experience. Those who accept that some benefits have accrued attach a preponderant role to social factors such as good housing, good nutrition giving greater resistance to infection, improved hygiene, and so on; and they regard the strictly medical contribution as marginal. Another line of criticism is that the exercise of scientific medicine tends to make doctors callous; that doctors increase their influence at the expense of the autonomy of the patient; and that technologically based medicine is too expensive. A further suggestion, on which I have already touched, is that doctors in the pursuit of cure are neglecting prevention. I tried to answer some of these criticisms in my Rock Carling lecture of 1984, under the somewhat contrived title, $A n$ Anthology of False Antitheses, and I shall not repeat the effort here, since polemics are as tedious to write as to read. To answer criticisms of medicine is to be arrogant; to ignore them is to be complacent. By doing first one and then the other, I can enjoy the worst of both worlds. But let me indulge myself with one sentence from my previous attempt: "The true antithesis of 'caring medicine' is not 'scientific medicine,' or 'high technology medicine,' or 'hospital medicine,' or 'academic medicine,' or 'orthodox medicine'; it is, quite simply, 'bad medicine."' There is a fortunate provision in the Roman church that the effectiveness of absolution depends on the sincerity of the penitent and not on the immaculacy of the priest. There is a half analogy here with the medical process - the outcome of any episode of illness depends, nine times out of ten, on what the patient has actually got wrong with him; but for the vital $10 \%$ of episodes what the doctor does is critical, and depends more on his competence than on his moral character. In the past both orthodox medicine and alternative medicine have benefited greatly from the frequency with which nature effects a cure; the new thing is that, as Beeson showed, the number of conditions in which what is done can critically affect the outcome is now considerable. It was possible in the past for a cynic to say, "Though there is a great difference between a good and a bad doctor, there is not much difference between a good doctor and no doctor at all." The first of these propositions remains true, but the second is in an increasing number of situations false.

From Recollections and Reflections by Douglas Black. Published under the BMF's Memoir Club imprint. ISBN 072790209 1. Price: Inland £14.95 abroad £17.50; USA \$29.00. BMA members: Inland £13.95; abroad £16.50; USA $\$ 27.00$. 